\title{
APPLICATION OF THE COASTAL STORM IMPULSE (COSI) PARAMETER TO PREDICT COASTAL EROSION
}

\author{
David R. Basco, Ph.D., P.E. ${ }^{1}$ and Robert A. Walker, P.E. ${ }^{2}$
}

\begin{abstract}
A new coastal storm-strength parameter, the Coastal Storm Impulse (COSI) parameter, was introduced at the ICCE 2006 (San Diego) and further discussed at the ICCE 2008 (Hamburg). COSI is based on the conservation of linear, horizontal momentum to combine storm surge, wave dynamics, and currents over the storm duration. Both tropical storms (hurricanes) and extra-tropical storms (northeasters) can produce similar COSI parameters that range from $0.69 * 10^{\wedge} 6 \mathrm{~N}-\mathrm{m} / \mathrm{hr}$ to $49.72 * 10^{\wedge} 6 \mathrm{n}-\mathrm{m} / \mathrm{hr}$ with lognormal distribution. Potential implications of such a storm classification system include the evaluation of coastal structures and coastal infrastructure, as well as providing a universal storm strength indicator that is directly tied to coastal physical parameters and not limited to wind speed. This paper explores the application of COSI to predict coastal erosion along the sub-aerial ocean beach in Duck, North Carolina on the east coast of the United States. Data for the 10-year study period (1994 to 2003) has been analyzed to produce 249 storms for study of coastal erosion. When profile response to coastal storms was assessed through a pre- and post-storm volumetric determination, mixed results showing both erosion and accretion were observed. The paper also explores the possible explanations and implications of these findings.
\end{abstract}

Keywords: coastal storm; beach erosion; storm surge; wave height; duration; momentum; impulse

\section{INTRODUCTION}

Quantification of the hydrodynamic intensity of coastal storms is of interest in Coastal Engineering. Increased wave heights, elevated water levels, and strong currents over the duration of the storm event may cause beach erosion and damage to property and infrastructure. In general, the more intense or severe the storm event is, the greater the resulting erosion or damage will be.

All four hydrodynamic variables-waves, water levels, currents and duration-have been combined into the Coastal Storm Impulse (COSI) parameter (Basco and Klentzman, 2006; Basco, Mahoudpour, and Klentzman, 2008). The COSI parameter applies the principle of conservation of momentum to physically combine the hydrodynamic variables per unit width of shoreline. This total momentum is then integrated over the duration of the storm to determine the storm's impulse to the coast. Figure 1 schematically illustrates how the offshore storm momentum is reduced to zero after impacting the coast. This change of momentum is the impulse produced by the storm. Correlations of the total storm magnitude (as represented by the COSI parameter) with beach erosion (or property/infrastructure damage) may then be possible for historical events and as a predictive tool for future storms.

This paper applies the COSI parameter to predict beach erosion (or accretion?) at the U.S. Army Corps of Engineers (USACE) Field Research Facility (FRF) in Duck, North Carolina. The hypothesis is that as the COSI parameter increases (that is, as the strength of the storm increases) the volume of erosion on the sub-aerial beach also increases.

Section 2 presents a brief review of the literature; most previous efforts used the amount of beach erosion (or property/infrastructure damage) to classify storm intensity, which is the opposite of what is studied in this paper.

The present method to calculate the COSI parameter is summarized in Section 3. New methods for calculating the storm impulse to the coast are being investigated. The FRF data set for sub-aerial, beach profiles is presented in Section 4, and volume change during a storm event is then summarized in Section 5. Possible explanations for the results (both erosion and accretion conditions were found) are then discussed in Section 6. Our conclusions, ongoing research efforts, and recommendations follow in Section 7.

\footnotetext{
${ }^{1}$ Department of Civil \& Environmental Engineering, Old Dominion University, Norfolk, Virginia 23529, USA

${ }^{2}$ Anchor QEA, 26300 La Alameda, Suite 202, Mission Viejo, California 92691, USA
} 


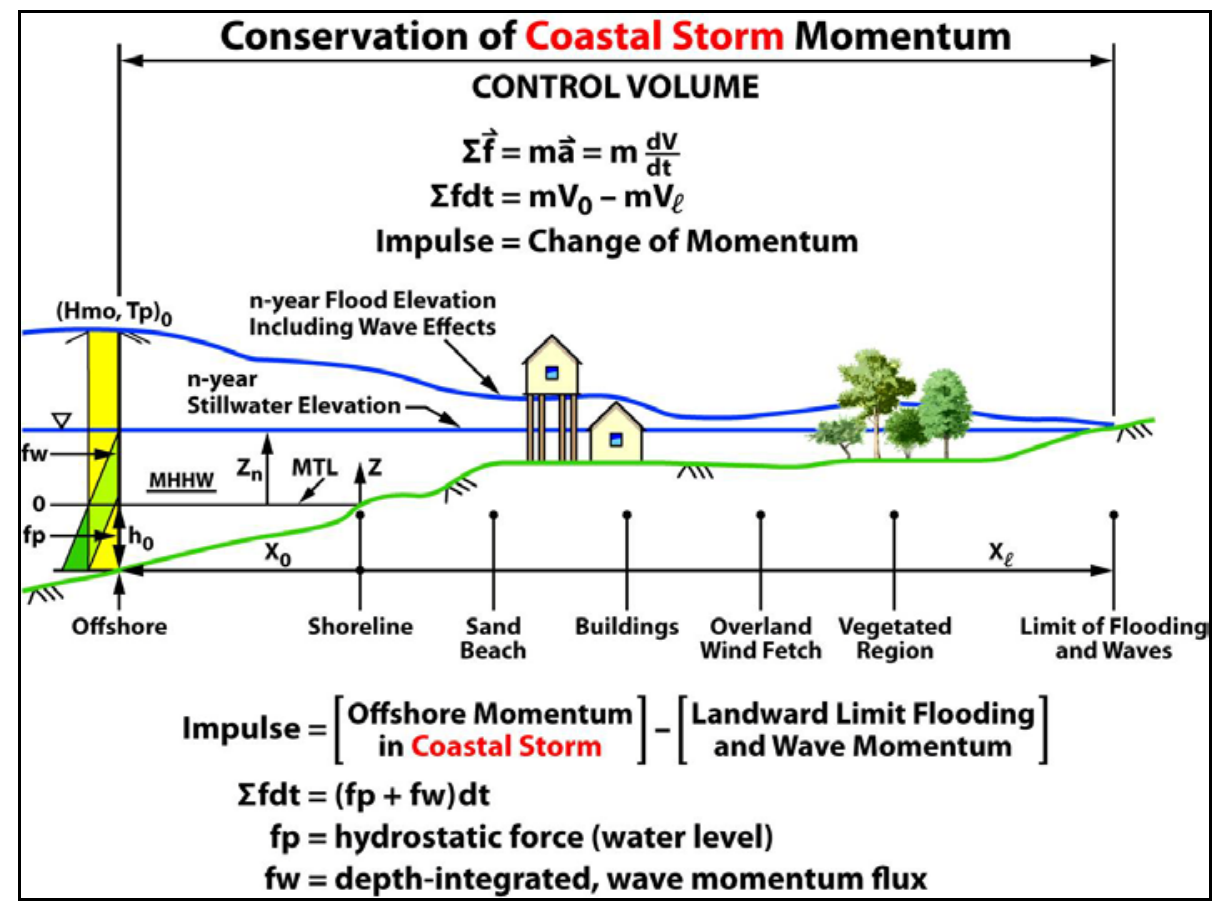

Figure 1. Control volume graphic illustrating offshore, water level, and wave forces impacting a slice of the coast.

\section{LITERATURE REVIEW}

Surprisingly, the threshold values for the hydrodynamic variables in a coastal storm are rarely defined. In no previous case have all four variables been considered together and combined in a physically meaningful manner except for the above referenced papers on the COSI parameter. A comprehensive literature review is currently underway that includes the following sub-topics: (1) definition of a coastal 'storm'; (2) storm waves; (3) storm water level and surge; (4) storm duration; (5) storm currents; (6) storm size; (7) storm consequences; and (8) storm indices.

The full literature review of coastal storms will be submitted for possible presentation at ICCE 2012. Only a few key references are cited in this paper. The most often-cited threshold variable to define when a coastal storm begins is the wave height.

\subsection{Storm Waves}

Dolan and Davis (1992) defined the start of a coastal storm as when the significant wave height exceeded 1.5 meters (5 feet) in "deep water" for the middle Atlantic Ocean coastal region of the United States. They claimed that wave heights greater than 1.5 meters result in "... measurable beach face erosion along the North Carolina coast” (p.842) although no profile data is presented. In this same region, since 1985, the U.S. Army Corps of Engineers FRF has employed a measured, threshold, significant wave height value of 2.0 meters (6.6 feet) at the end of the research pier (water depth 7.6 meters; see FRF, 1985) to identify and extract a "storm" from the overall dataset (http://frf.usace.army.mil/storms.shtml). This threshold wave height is calculated as the long-term mean wave height plus two times the standard deviation of the mean and currently $0.9 \mathrm{~m}+2 * 0.57 \mathrm{~m})=$ 2.04 meters (Birkemeier, 2010, personal communication). The storm “ends” whenever the significant wave height drops below 2.0 meters. The identical calculation method to identify the threshold wave height is employed by the Universitat Politecnica de Catalunya (Mendoza, 2010, personal communication) for the Catalan coast of Spain.

Near shore waves are stronger on the West Coast of the United States in the Pacific Ocean. Seymour et al. (1984) discuss measured "large waves" in Southern California from 1900 to 1983 and arbitrarily defined a major storm event when the significant wave heights exceeded 3.0 meters (10 feet) for more than 9 hours. The New South Wales (NSW) Australia Department of Natural Resources has measured deep-water wave heights since 1974 at seven locations in the Tasman Sea. The Peak-OverThreshold analysis method is employed (Kamphuis, 2010) to estimate recurrence intervals of extreme 
wave height events. Individual storm events are defined when the significant wave heights are higher than 3.0 meters (You and Lord, 2008).

Clearly, the threshold wave height to define a coastal storm is site-specific and can be theoretically determined from long-term wave data or wave information.

\subsection{Storm Water Levels and Surge}

Threshold water levels are closely associated with astronomical tidal elevations and physical processes (wind stress, atmospheric pressure gradients, and wave setup) that elevate the normal tidal levels to impact man's activities at the coast. Acqua alta (high water) events in San Marco Square in Venice, Italy (The Organizing Committee, 1992), are a good example. Whenever the water levels in the Square impede normal foot traffic of citizens and tourists, a coastal 'storm' is felt to be present in the Adriatic Sea. In urban coastal areas throughout the world, the threshold, coastal "storm" water levels are often defined by impacts to transportation infrastructure (roads, bridges, railway lines, etc.). When roads are flooded deep enough to impede traffic, a coastal "storm" is said to exist. Low-lying transportation corridors are constructed above the normal, high tide levels plus some additional elevation at a given frequency of exceedance that is based on local economic and environmental consequences. Therefore, there is generally no standard for the elevation of the water level above the mean high water (MHW) tidal elevation to be the threshold defining a storm event.

Because storm high water level events are often directly correlated with large wave height events, storm water level is not normally employed as a threshold to signify a "storm" event in the literature. Storm surge, though, can be employed to define storm duration.

\subsection{Storm Duration}

To rank storms for a statistical analysis, Munger and Kraus (2010) defined the storm duration as the amount of time the storm surge exceeded 0.3 meters (1.0 feet). This storm duration definition was different than most in that it was not dependent on wave height. Miller and Livermore (2008) state that when threshold (wave height or water level) exceedances are separated by less than 72 hours, they are considered to be the same storm event; however, they failed to specify the threshold for water level.

The length of storm durations is different between tropical storms (hurricanes, typhoons) and extra-tropical storms (low pressure fronts). Extra-tropical storms have relatively longer durations (days) whereas tropical storms are normally fast moving with short durations measured in hours at a specific coastal site. The minimum duration for consideration of a single storm is subject to debate; however, the need for statistical independence exists for measured conditions (wave heights, water levels, etc.) for an exceedance frequency analysis (that is, the POT method). Kamphuis (2000) states the minimum duration must be greater than one hour.

\subsection{Storm Currents}

Cross-shore (undertow, rip) and longshore currents increase significantly during storm events; however, no threshold values have been found in the literature.

\subsection{Storm Consequences and Indices}

Most sources reviewed attempt to define the strength or severity of a coastal storm by the level of consequences (such as beach erosion, property damage, and infrastructure damage) and not by the storm physics. See Munger and Kraus (2010) for an example of the recent summary of the literature in this regard. This approach depends upon many variables at the site (pre-storm sand volume, urban, or rural, or agricultural populations) and not the storm physics.

\subsection{Storm Size.}

No published references on the size of the coastal storm, as measured by the length of coastal shoreline impacted by a single event, could be located for this paper.

\section{THEORY OF THE COSI PARAMETER}

\subsection{Storm Surge Momentum Parameter}

The horizontal momentum for free surface flow is found by integrating the pressure distribution and the velocity distribution in the shore normal direction over the water depth.

$$
1 / 2 \rho g\left(s+h_{0}\right)^{2}+\rho\left(s+h_{0}\right) V^{2}
$$


where, $s$ is the storm surge (observed - predicted water level), $h_{0}$ is the mean water level, $V$ is the depth-averaged current, $\rho$ is the fluid mass density and g, the gravitational constant. Expanding the first term, neglecting the current momentum, and subtracting the mean, hydrostatic pressure term gives

$$
f_{S}(t)=1 / 2 \rho g\left(s+h_{o}\right)^{2}-1 / 2 \rho g\left(h_{0}\right)^{2}
$$

where $f_{s}(t)$ is the horizontal, storm surge momentum above the normal, mean water level $\left(h_{0}\right)$ for any time, $t$ during the storm event.

\subsection{Wave Momentum Flux Parameter}

For storm events we herein assume that the wave crests are approximately parallel to the shoreline at the shallow water depths of interest for definition of the wave momentum flux parameter. Depthintegrating and time-averaging the instantaneous horizontal flux of momentum beneath the waves results in the radiation stresses. Gradients in the shear stress components force the long shore currents and gradients in the shore normal components of the radiation stress create wave set down and setup. Hughes (2004) argued that the depth-integrated wave momentum flux varied significantly over the wave length (or period) so that the wave-averaged value (that is, the radiation stress) is relatively small compared to the maximum wave momentum flux values. For this reason, Basco and Klentzman (2006) adopted the maximum, depth-integrated, wave momentum flux parameter, $\mathrm{M}_{\mathrm{F}}(\mathrm{t})$ for implementation in the COSI parameter. For highly nonlinear waves (Fourier wave theory) in shallow water, Hughes (2004) empirically derived $M_{F}(t)$ with two coefficients for regular waves $\left(A_{0}, A_{1}\right)$ :

$$
\mathrm{M}_{\mathrm{F}}(\mathrm{t})=\left(\rho \mathrm{gh}^{2}\right) \mathrm{A}_{0}\left(\mathrm{~h} / \mathrm{gT}^{2}\right)^{-\mathrm{A}}{ }_{1}
$$

where:

$$
\begin{aligned}
\mathrm{A}_{0} & =0.6392(\mathrm{H} / \mathrm{h})^{2.0256} \\
\mathrm{~A}_{1} & =0.1804(\mathrm{H} / \mathrm{h})^{-0.391} \\
\mathrm{H} & =\text { wave height, regular waves } \\
\mathrm{T} & =\text { wave period, regular waves }
\end{aligned}
$$

For irregular waves, Hughes (2004) recommended using the frequency-domain parameters, Hmo and Tp in Equations (3), (4), and (5).

\subsection{The CoSI Parameter}

The total storm momentum is simply the sum of the storm surge momentum parameter, $f_{s}(t)$ and the maximum wave momentum parameter, $\mathrm{M}_{\mathrm{F}}(\mathrm{t})$. The COSI parameter ( $\mathrm{I}_{\mathrm{S}}$ ) is then found by integrating in time over the storm duration, $\mathrm{D}$ as defined in the following equation.

$$
I_{S}=\int\left[f_{S}(t)+M_{F}(t)\right] d t
$$

where:

$$
\begin{aligned}
& \mathrm{IS}_{\mathrm{S}}=\text { the COSI parameter } \\
& \mathrm{D}=\text { the duration of the storm }
\end{aligned}
$$

\subsection{Storm Definition}

Following Dolan et al. (1987) and Dolan, Lins, and Hayden (1988) for Mid-Atlantic region coastal storms, the start of a coastal storm is defined as when wave heights reach at least 1.6 meters in deep water with no storm surge. A slight correction for storm surge momentum is included to reduce the wave height required for defining a storm event. The minimum storm duration was 6 hours, and 48 hours was chosen as the interval between storm events. See Klentzman (2007) for complete details. 


\section{THE FRF DATA SET}

The USACE FRF is located on the Atlantic Ocean in Duck, North Carolina (see Figure 2). Since 1981, the FRF has collected near shore oceanographic data on a routine basis. This data set now covers nearly thirty years and is unmatched worldwide in terms of accuracy and temporal coverage. When combined with other near shore data collected such as wave height and period, and water level, the result allows a comprehensive evaluation of the impact of storms to the near shore profile, as well as systematic analysis of longer-term natural sediment transport processes that move sediment in between storm events and tend to fluctuate seasonally. This data is being used to refine theories of near shore morphological change, provide a continuous data set for developing and testing numerical simulations of near shore morphology, and support additional coastal research such as the topic introduced in this paper.

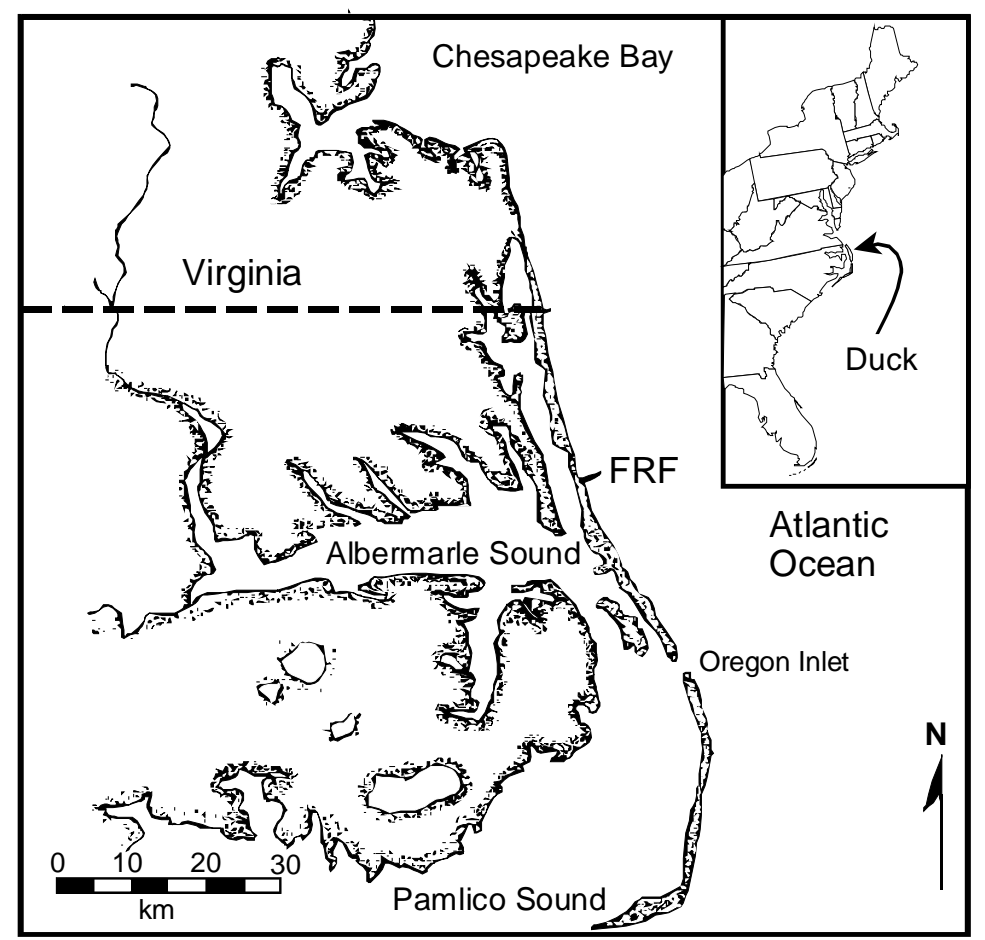

Figure 2. Site location map of the USACE Field Research Facility. (Courtesy USACE FRF)

The collection of beach and near shore profile data at the FRF is conducted over a series of 26 shore perpendicular profile lines (see Figure 2), collected monthly, and extending from the dune line to approximately 950 meters offshore to a depth of at least 8 meters. Of the 26 lines, four (profile Nos. 58, 62, 188 and 190) are surveyed biweekly as part of a "four-line survey."

The surveys are conducted with the Coastal Research Amphibious Buggy (CRAB), a 10.7 meter tall amphibious tripod which travels across the beach and near shore slope on pneumatic tires. Benefits of using the CRAB include an uninterrupted stream of survey data on a single positioning system configuration, and the ability to collect data during turbulent conditions. With a maximum significant wave height for operation at 2 meters (6 feet), the CRAB is capable of operating in all but the most severe storms at the FRF.

In an effort to negate the effects of the FRF's pier, a robust pile-supported structure that extends 1,000 meters offshore to a depth of more than 6 meters, profile No. 188 was chosen for use in this analysis. Profile 188 is located approximately 500 meters to the south of the pier and is arguably the more studied section of the beach at the FRF.

Because this analysis focused on the morphological change of the sub-aerial beach only, seaward and landward limits of the sub-aerial beach were defined as pertains to this analysis. The limit between sub-aerial beach and subaqueous beach was defined as the mean low water (MLW) elevation, per NOAA Tidal Benchmark in Duck, North Carolina (Station ID: 8651370) for the 1983-2001 tidal epoch. Only material located above this vertical plane was considered when calculating volumetric change. Data was also bound in the landward direction by limiting data to only beyond 67 meters from 
the survey baseline. This landward limit was chosen such that all surveys utilized in the analysis could represent the same landward extent.

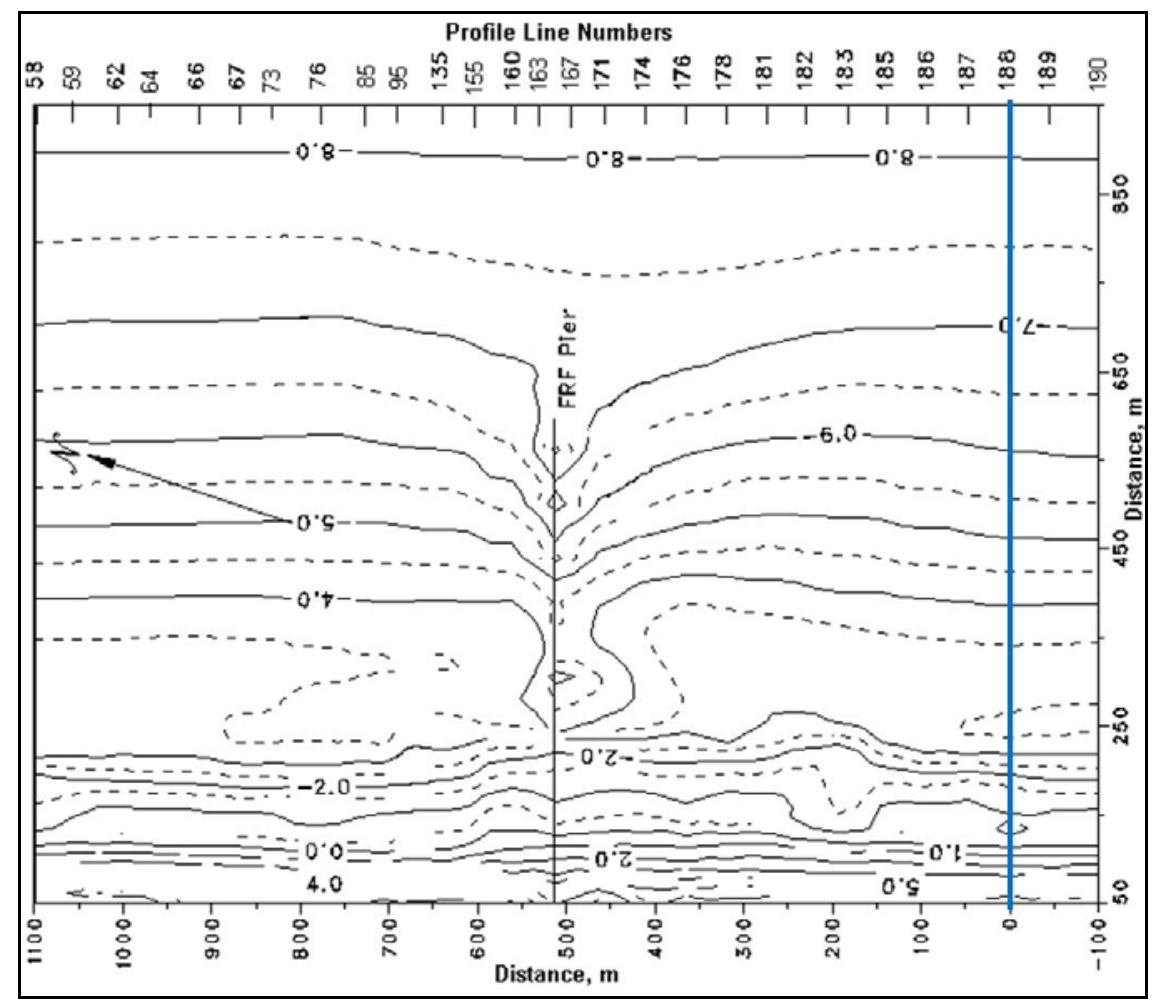

Figure 3. Beach and near shore profile data is collected across 26 survey transects spanning 1,200 meters. (Courtesy USACE FRF)

\section{DATA ANALYSIS AND RESULTS}

Using wave and storm surge data collected at the FRF, 249 storms were identified over the study period (1994 to 2003), based on the previously mentioned definition of a storm. For each storm, the total impulse, or COSI parameter, was determined based on maximum wave height and elevated water level over the defined duration of the storm. The resulting storm set consisted of both tropical (hurricanes) and extra-tropical (nor'easters) with resulting COSI values ranging from $0.69 * 10^{\wedge} 6 \mathrm{n}$ $\mathrm{m} / \mathrm{hr}$ to $49.72 * 10^{\wedge} 6 \mathrm{n}-\mathrm{m} / \mathrm{hr}$. Near shore profile data for the study period was compiled and subsequently compared with the storm data set. In many cases, more than one identified storm occurred between two subsequent surveys, compromising any direct correlation with storm impulse and volume change of the sub-aerial beach. A summary of storms, survey events and single storms between two survey events is presented in Table 1. As shown, the resulting set of paired storms and pre/post surveys was rather limited, providing a set of 65 storms to carry through the analysis of volumetric change due to coastal storm impacts.

\begin{tabular}{|l|l|l|l|}
\hline \multicolumn{4}{|c|}{ Table 1. Storm and near shore profile inventory for the study period of 1994-2003. } \\
\hline Year & No. of Surveys & No. of Storms & No. of Single Storms bracketed between 2 surveys \\
\hline 1994 & 19 & 25 & 5 \\
1995 & 18 & 28 & 6 \\
1996 & 23 & 26 & 14 \\
1997 & 18 & 31 & 3 \\
1998 & 21 & 28 & 10 \\
1999 & 22 & 27 & 8 \\
2000 & 17 & 18 & 7 \\
2001 & 20 & 26 & 3 \\
2002 & 16 & 34 & 5 \\
2003 & 13 & 27 & 4 \\
\hline
\end{tabular}


Given the set of identified storms for subsequent beach profile analysis, surveys were further filtered and formatted for use with the Beach Morphology and Analysis Package (BMAP). In carrying out this more detailed analysis of survey data and COSI values, some storms were discarded from the data set due to overlapping storm and survey dates, inadequate near shore profile data, or similar concerns. The final tabulation of successful storm events and comprehensive pre- and post-storm survey data resulted in a set of 48 paired combinations of COSI parameters with volumetric change of the sub-aerial beach. The 48 storm events, listed with the observed volume change in cubic meters per meter $\left(\mathrm{m}^{3} /\right.$ mof the sub-aerial beach and the respective COSI parameter based on hydrodynamic conditions is presented in Table 2.

\begin{tabular}{|c|c|c|c|}
\hline Storm No. & Date & $\begin{array}{l}\text { Volume Change } \\
\left(\mathrm{m}^{3} / \mathrm{m}\right)\end{array}$ & $\begin{array}{l}\text { Coastal Storm Impulse (COSI) } \\
\left({ }^{\star} 10^{\wedge} 6 \mathrm{n}-\mathrm{m} / \mathrm{hr}\right)\end{array}$ \\
\hline 1 & January 3, 1994 & -10.4 & 3.7 \\
\hline 2 & March 1, 1994 & 4.8 & 8.2 \\
\hline 3 & March 10, 1994 & 0.6 & 1.3 \\
\hline 4 & April 22, 1994 & 0.2 & 1.1 \\
\hline 5 & May 18, 1994 & -1.1 & 12.2 \\
\hline 6 & April 10, 1995 & -11.9 & 1.4 \\
\hline 7 & June 13, 1995 & -17.2 & 1.4 \\
\hline 8 & June 28, 1995 & 19.4 & 2.6 \\
\hline 11 & August 28, 1995 & -27.5 & 5.5 \\
\hline 13 & February 16, 1996 & -3.9 & 5.5 \\
\hline 14 & February 29, 1996 & -4.1 & 0.9 \\
\hline 15 & March 29, 1996 & -97.9 & 8.8 \\
\hline 16 & April 6, 1996 & 6.1 & 1.3 \\
\hline 17 & May 28, 1996 & 5,2 & 1.9 \\
\hline 18 & July 12, 1996 & -0.0 & 1.9 \\
\hline 19 & August 14, 1996 & -4.4 & 0.8 \\
\hline 20 & September 18, 1996 & 9.3 & 0.7 \\
\hline 21 & October 19, 1996 & -3.0 & 0.9 \\
\hline 22 & November 2, 1996 & 3.6 & 2.3 \\
\hline 23 & November 15, 1996 & -10.5 & 23.4 \\
\hline 24 & November 26, 1996 & 19.7 & 3.2 \\
\hline 26 & January 9, 1997 & 2.3 & 1.0 \\
\hline 27 & September 3, 1997 & -14.3 & 3.3 \\
\hline 28 & October 15, 1997 & -13.6 & 21.2 \\
\hline 29 & January 14, 1998 & 0.1 & 29.4 \\
\hline 31 & March 8, 1998 & 6.2 & 2.1 \\
\hline 32 & March 20, 1998 & 8.5 & 4.3 \\
\hline 33 & April 4, 1998 & -6.8 & 7.8 \\
\hline 34 & April 10, 1998 & -4.4 & 20.5 \\
\hline 35 & June 28,1998 & 5.2 & 0.8 \\
\hline 36 & August 19, 1998 & -6.0 & 0.9 \\
\hline 37 & August 26, 1988 & -9.3 & 11.8 \\
\hline 38 & September 4, 1998 & -10.0 & 1.8 \\
\hline 39 & March 7, 1999 & -23.4 & 17.9 \\
\hline 40 & March 26, 1999 & -0.6 & 8.8 \\
\hline 41 & May 13, 1999 & 22.6 & 19.7 \\
\hline 42 & August 30, 1999 & -7.7 & 49.7 \\
\hline 46 & November 30, 1999 & -4.9 & 10.9 \\
\hline 50 & April 25, 2000 & 15.8 & 9.5 \\
\hline 51 & May 29,2000 & -12.6 & 14.8 \\
\hline 52 & September 25, 2000 & 10.5 & 13.7 \\
\hline 53 & November 25, 2000 & -0.9 & 4.6 \\
\hline 54 & September 11, 2001 & -0.1 & 25.9 \\
\hline 57 & March 2, 2002 & 12.7 & 2.6 \\
\hline 58 & May 18, 2002 & -6.3 & 3.1 \\
\hline 59 & June 7, 2002 & 0.2 & 5.8 \\
\hline 63 & June 16, 2003 & -8.7 & 2.3 \\
\hline 64 & September 6, 2003 & -14.6 & 48.2 \\
\hline
\end{tabular}


The pre- and post-storm profiles were compiled into BMAP and volumes were determined for all survey events. When pre-storm profiles were compared against post-storm profiles for each event, the data showed a variety of both erosion and accretion across the study period. In total, erosion of the sub-aerial beach was observed for 29 events, while 19 storm events were observed to cause accretion of the sub-aerial beach. Example plots of pre- and post-storm profiles for storms demonstrating erosion and accretion are shown in Figures 4 and 5, respectively.

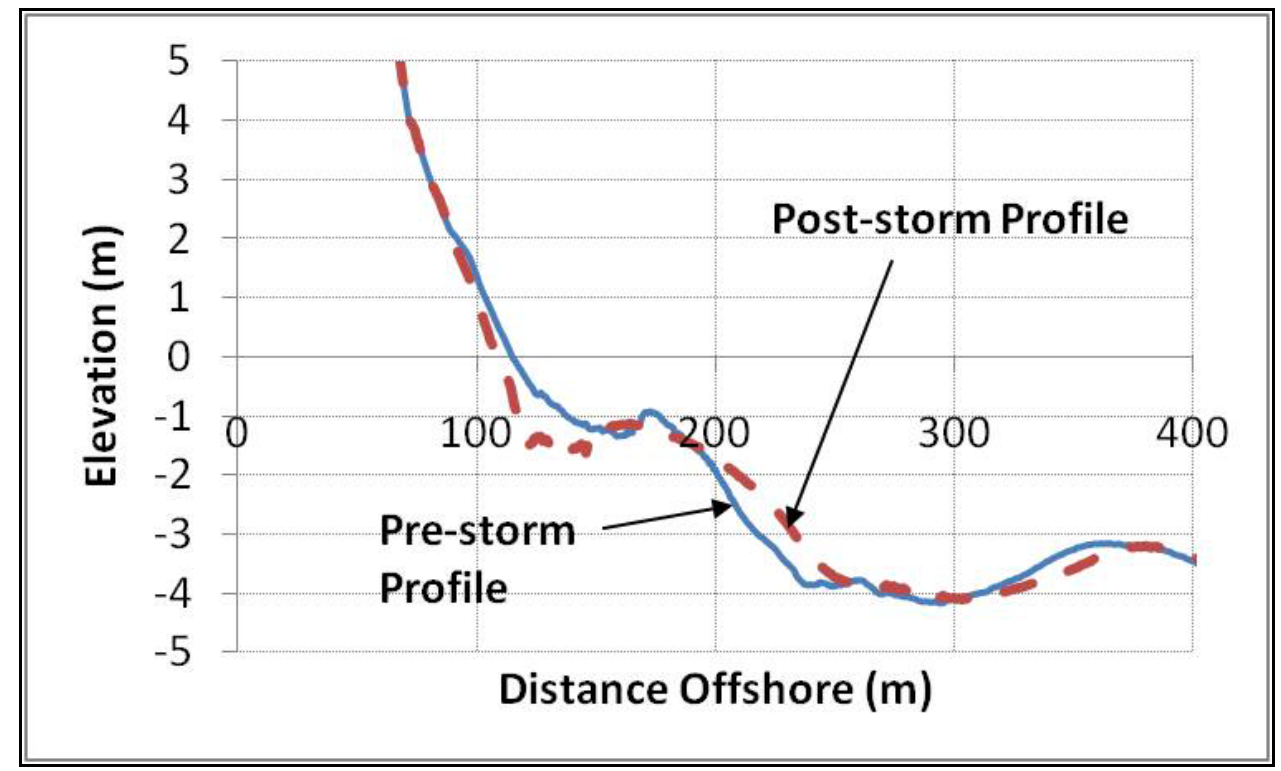

Figure 4. Pre- and post-storm survey comparison for storm demonstrating erosion of the sub-aerial beach (November 14-23, 1996).

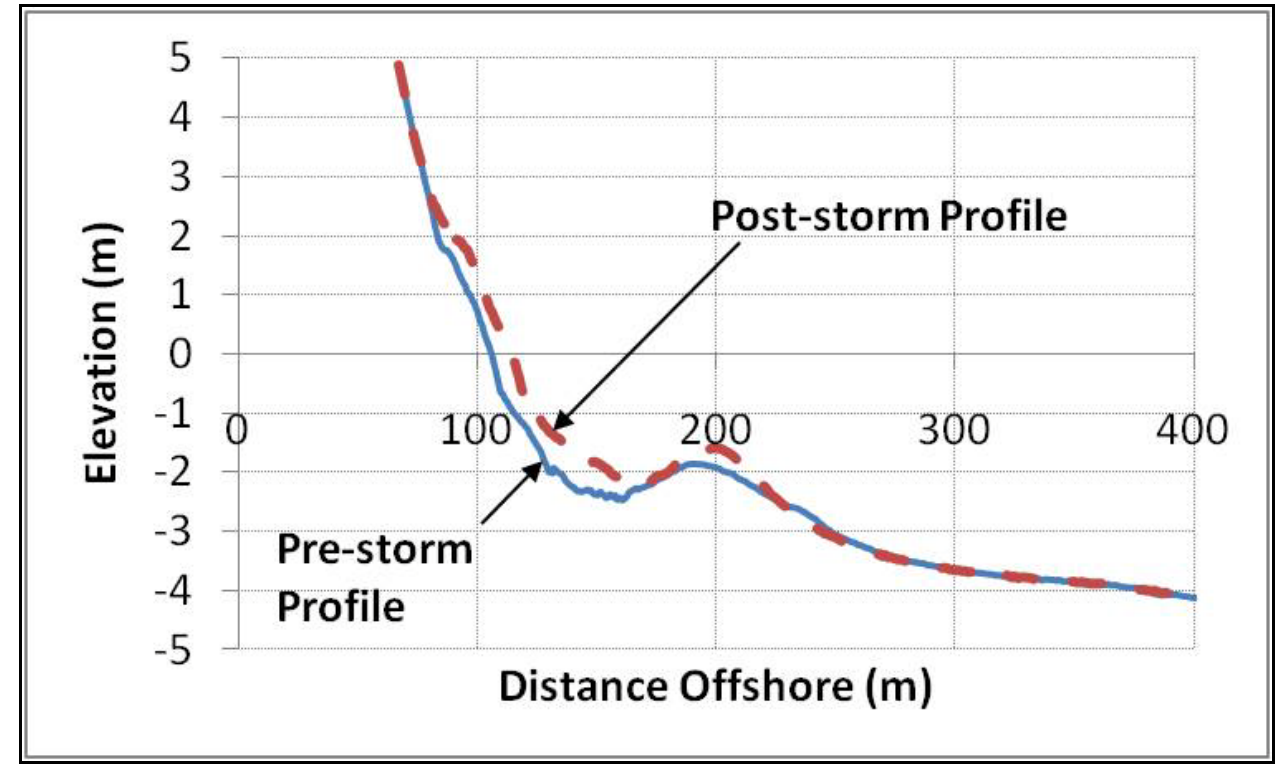

Figure 5. Pre- and post-storm survey comparison for storm demonstrating accretion of the sub-aerial beach (June 27-29, 1995).

Based on the results of the volumetric profile analysis, storms were categorized as either causing erosion or accretion. The volume loss due to erosive storms was then plotted against their respective COSI values. No clear correlation was evident from this procedure. Similarly, the accreted volume for those storms that demonstrated a gain in volume on the sub-aerial beach was plotted separately against the respective storm's COSI value. Again, based on this simplistic procedure and not considering any 
external effects, no clear relationship was evident for coastal storm impulse and sediment deposition on the sub-aerial beach. A graphical presentation of all storms, both representing erosion (red diamonds) and accretion (green squares), is plotted in Figure 6.

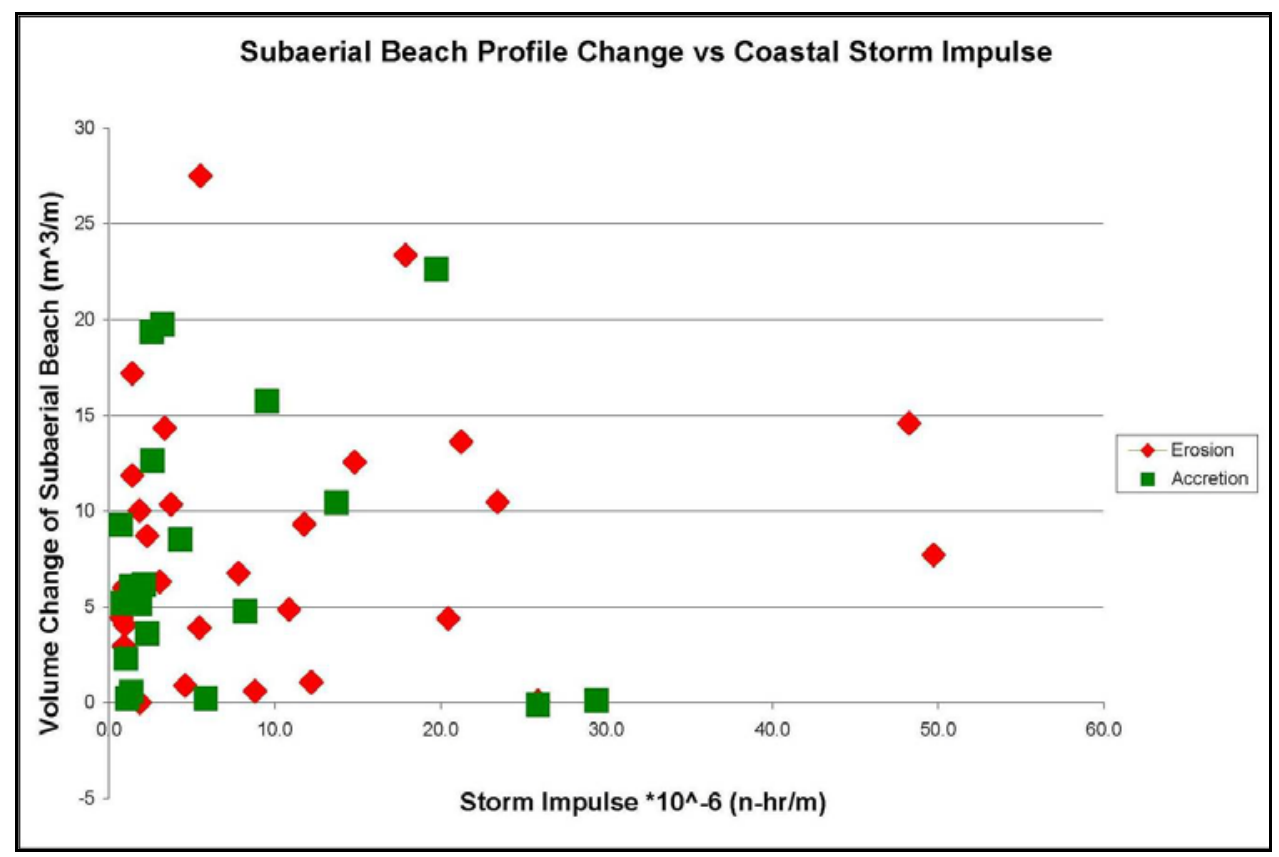

Figure 6. Plot of the volumetric change of the sub-aerial beach vs the total coastal storm impulse.

In an effort to expand the paired data set of coastal storm impulse and volume change, storms across the study period were then grouped together in a systematic way. For storms with a COSI value greater than $1.5^{*} 10^{\wedge} 6 \mathrm{n}-\mathrm{m} / \mathrm{hr}$ the pre- and post-storm profiles bounding the storm would be compared assuming all other COSI values for additional storms within the survey period had COSI values no greater than $1.0^{*} 10^{\wedge} 6 \mathrm{n}-\mathrm{m} / \mathrm{hr}$. This seemingly arbitrary process resulted in an additional 17 representative "storms" that were then compared with the corresponding COSI value for this storm. The thought process was that the lower strength storms, with typical COSI values of $0.5^{*} 10^{\wedge} 6 \mathrm{n}-\mathrm{m} / \mathrm{hr}$, were not contributing significantly to morphologic changes of the sub-aerial beach. Similar to the single storm analysis, this process resulted in no clear correlation between COSI values and volumetric change in the sub-aerial beach.

\section{POSSIBLE EXPLANATION OF RESULTS}

This analysis began by investigating the relationship between coastal storm impulse, and a storms impact to the volume change of the sub-aerial beach. Upon identification of appropriate storm conditions and survey intervals to allow such an analysis, both erosion and accretion were observed in resulting calculations in a seemingly random fashion. There were high COSI values that showed both high and low amounts of volume change, for both erosion and accretion. Likewise, storms with low COSI values produced high and low amounts of volume change with a variety of cases of both erosion and accretion.

The Dean Number, relating wave height, period and fall velocity has often been cited to predict the direction (offshore or onshore) for sediment transport (Dean, 1973; Kraus et al., 1991). It can also be employed to classify beaches as reflective, intermediate, or dissipative types (Wright and Short; 1984). Depending on the condition of the pre-storm profile, how the coast responds to a given storm could change. For example, if the pre-storm profile was already in a dissipated state, this could explain why for the same storm intensity (or COSI parameter) the beach volume change could be positive indicating accretion.

Qi et al. (2010) applied the Wright and Short model to the beaches of south China. This investigation indicated that a "dissipative" beach would be more likely to have minimal impacts due to the storm, while a "reflective" beach would tend to experience significant storm impacts. For the 
"intermediate" condition of a beach profile with a temporary bar system, the effects to the profile were that the bars would flatten and move seaward.

After an analysis of all contributing factors, the most logical explanation for these results of this analysis remained that the condition of the pre-storm profile played a key role in determining whether a storm would cause erosion or accretion. Munger and Kraus (2010) investigated the impact of storm intensity on the coast by assuming the same initial pre-storm condition for each storm event using a numerical beach profile model. This results in a high correlation between profile change and storm intensity, however may be providing some false implications. In reality, as presented in this paper, the pre-storm condition of the beach profile plays an important role in determining what impact a storm will have on the sub-aerial beach. If the pre-storm profile was representative of an already eroded shoreline, would an approaching storm cause less erosion than if it was a healthy beach? Or would a healthy beach, representative of typical "summer" conditions be less prone to erosion? An eroded shoreline in many cases would result in sediment being carried offshore to produce offshore "storm" bars. Such storm bars would likely dissipate the energy of a storm and therefore somewhat mitigate potential impact to the subaerial beach, should the storm bar not be present.

To further evaluate the potential impact of the pre-storm profile on the volume change of the subaerial beach, all pre-storm profiles for storms resulting in erosion were compared with storms resulting in accretion. Figure 7 presents the pre-storm profiles for all storms that demonstrated erosion of the subaerial beach. Figure 8 presents the pre-storm profiles for all storms that demonstrated accretion. With so many profiles plotted together, it is difficult to discern any notable difference between the two situations.

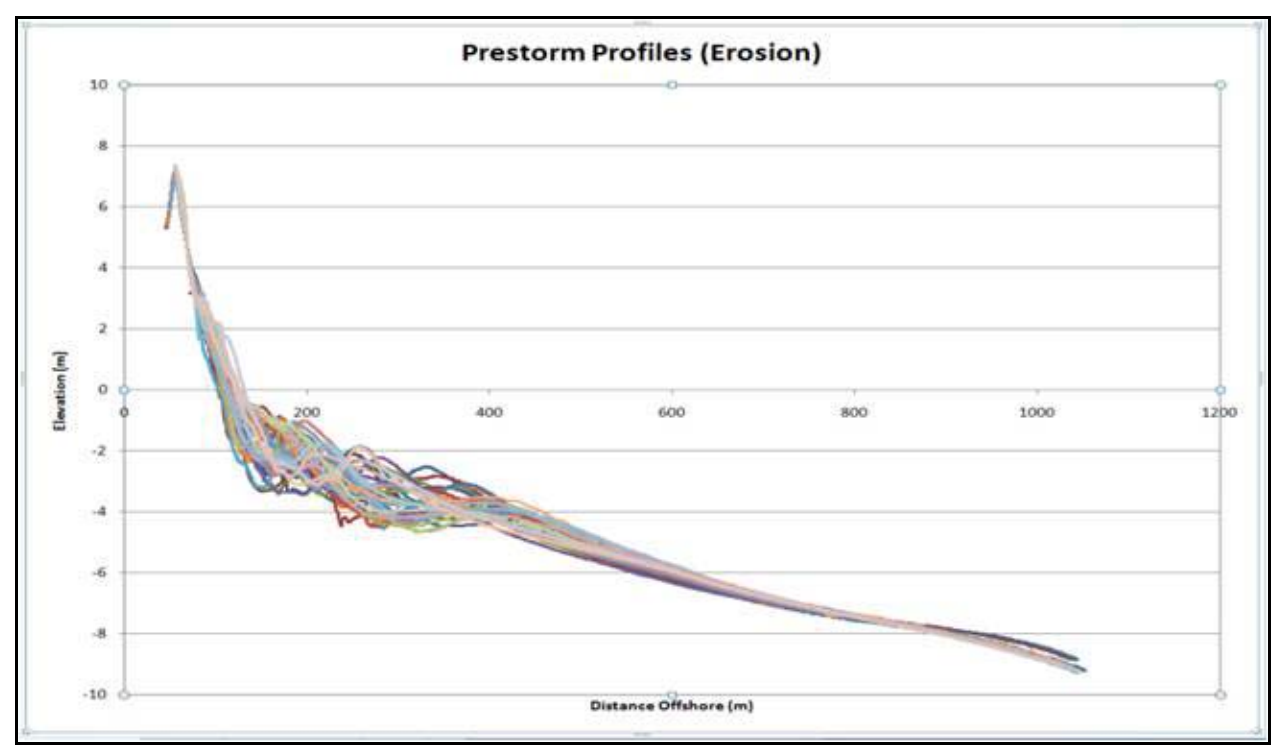

Figure 7. Plot showing all pre-storm profiles for storms that showed erosion of the sub-aerial beach. 


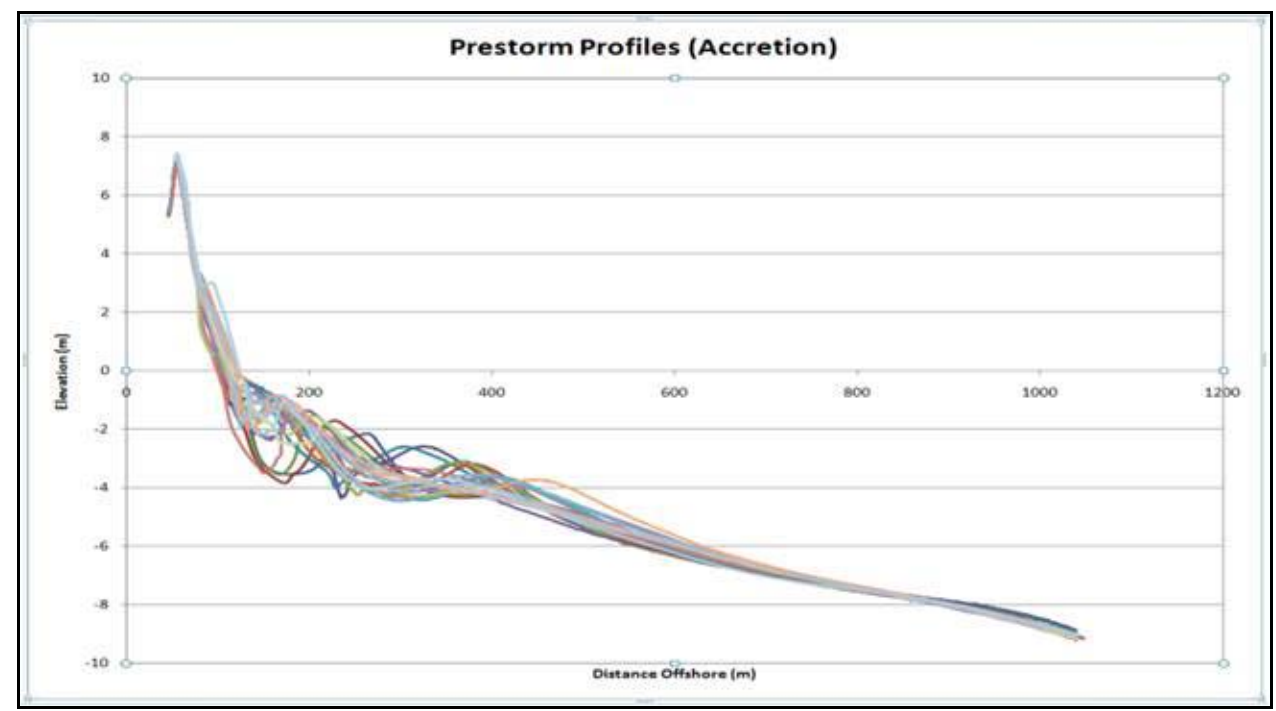

Figure 8. Plot showing all pre-storm profiles for storms that showed accretion of the sub-aerial beach.

In an attempt to further compare the pre-storm profiles for those storm events that produced erosion and accretion of the sub-aerial beach, the mean pre-storm profile was then produced for both conditions. Figure 9 below displays the results. Surprisingly, the mean pre-storm profile for storms resulting in erosion is almost undistinguishable from the mean pre-storm profile for storms that resulted in accretion. Focusing in on the swash zone, the slope of the mean "erosion" profile is 1:9, while the slope of the mean "accretion" profile is 1:12. Thus, based on this observation, the steeper pre-storm beach profile erodes while a flatter beach profile promotes accretion. This conclusion is exactly the opposite of what we expected.

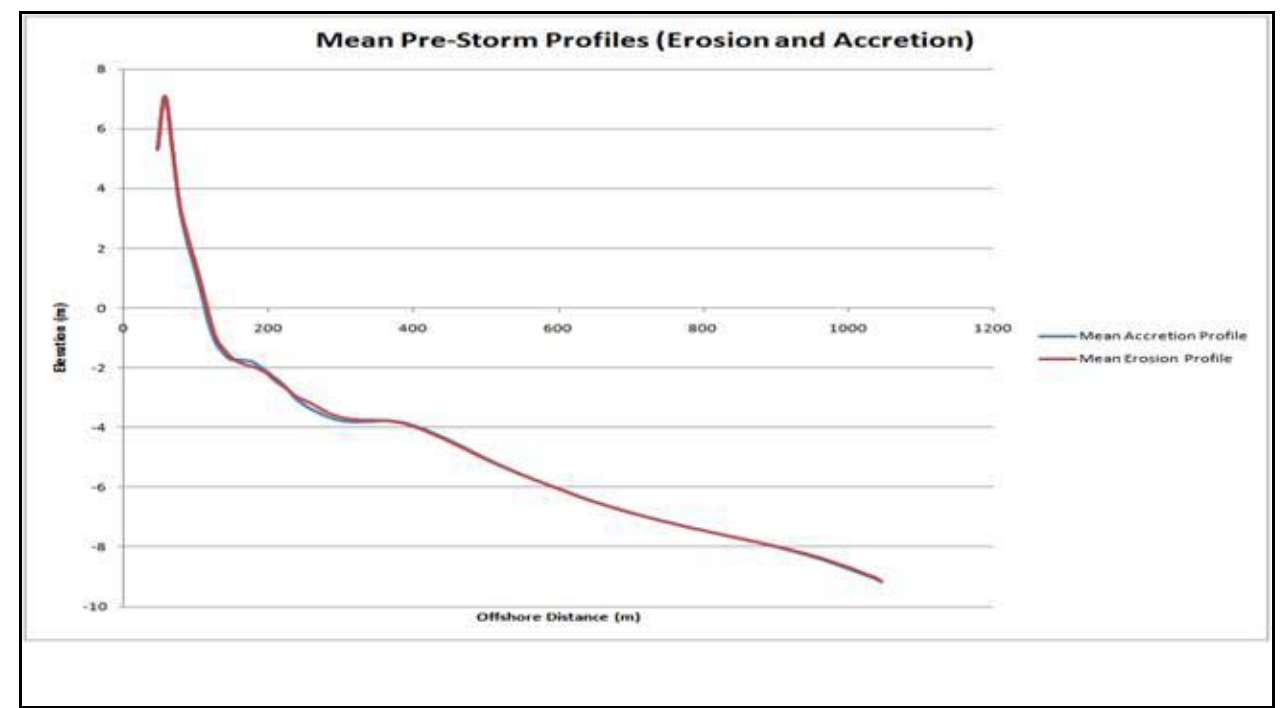

Figure 9. Plot showing mean pre-storm profiles for storms that showed (a) accretion and (b) erosion, of the sub-aerial beach. 


\section{CONCLUSIONS AND RECOMMENDATIONS}

Further analysis is needed and continues. Regarding the pre-storm beach conditions, we are investigating: (1) type of beach profile, namely, reflective, dissipative, or intermediate; (2) presence of near shore bars; (3) swash zone slopes for individual storm events; (4) shoreline changes during the time up to the pre-storm profile; and (5) adjacent profiles. We are also investigating the full profile out to closure depth regarding the full volume change (mass balance and/or imbalance) to learn about the contribution of longshore sediment transport. Finally, we are also investigating the COSI parameter for (1) the storm duration; (2) storm direction; (3) the relative contributions for wave momentum versus water level momentum; and (4) dividing the storm duration into two phases for (a) offshore and (b) onshore sediment transport conditions.

Unfortunately, we can offer no definitive explanation at this writing for why some storms produce erosion and some produce accretion for similar values of the COSI parameter.

\section{ACKNOWLEDGEMENTS}

Bill Birkemeier, US Army Corps of Engineers’ Field Research Facility

Ryan Turner, Graduate Student, Old Dominion University

\section{REFERENCES}

Basco, D.R., and Klentzman, C. 2006. On the Classification of Coastal Storms Using Principles of Momentum Conservation, Proceedings, ICCE 2006, San Diego, ASCE, NY, Vol 2, pp. 14071419.

Basco, Mahmoudpour and Kelentzman. 2008. Statistical Analysis of the Coastal Storm Impulse

(COSI) Scale at the Corps of Engineers, FRF, Duck NC, Proceedings, ICCE 2008, Hamburg, ASCE, NY, Vol. 6, 4134-4142.

Dean, R.G. 1973. Heuristic Models of Sand Transport in the Surf Zone, Proceedings, Conference

on Engineering Dynamics in the Surf Zone, Sydney, Australia, 208-214.

Dolan, R, Hayden, D., Bosserman, K., Lisle, L. 1987. Frequency and Magnitude Data on Coastal Storms, Journal of Coastal Research, vol. 3, no. 2. Charlottesville, VA, pp. 245-247.

Dolan, R., Lins, H., and Hayden, B. 1988. Mid-Atlantic Coastal Storms, Journal of Coastal Research, vol. 4 no. 3. Charlottesville, VA, pp. 417-433.

Hughes, S.A. 2004. Wave Momentum Flux Parameter: a Descriptor for Near Shore Waves, Coastal Engineering, vol. 51. Elsevier, pp. 1067-1084.

Kamphuis, W. 2010. Introduction to Coastal Engineering and Management, World Scientific, Inc., NJ, 2nd Edition.

Klentzman, C. 2007. Using Principles of Momentum Conservation to Develop Coastal Strom Impulse Scale (COSI), Unpublished, Ph.D. Dissertation, Old Dominion University, Norfolk, VA.

Kraus, N.C., M. Larson and D.L. Kriebel. 1991. Evaluation of Beach Erosion and Accretion Predictors, Proceedings, Coastal Sediments 1991, Seattle, ASCE, Seattle, 572-587.

Miller, J.K., Livermont, E. 2008. A Predictive Index for Wave and Storm Surge Induced Erosion, Proceedings, 31st Coastal Engineering Conference, ASCE, NY, pp 561-572.

Munger, S., and Kraus, N.C. 2010. Frequency of Extreme Storms Based on Beach Erosion at Northern Assateague Island, Maryland, Shore \& Beach, Vol.78, No.2. pp. 3-11.

Sallenger, A.H., Jr. 2000. Storm impact scale for barrier islands, Journal of Coastal Research, vol. 16, no. 3. West Palm Beach, pp. 890-895.

Seymour, R.J., Strange, R.R., III, Cayan, R., Nathan, R.A. 1984. Influence of El Ninos on California's Wave Climate, Proceedings, $19^{\text {th }}$ International Conf. on Coastal Engineering, ASCE, NY, Vol 1, pp 577-592.

The Organizing Committee. 1992. The Acqua Alta in Venice, Oct 4-7, 1992, Proceedings, International Conference on Coastal Engineering, ASCE, NY, vol 3.

Wright, L.D. and A.D. Short. 1984. Morphodynamic Variability of Surf Zones and Beaches, Marine Geology, Vol 56, 93-118.

You, Z.-J. and Lord, D. 2008. Influence of the El Nino-Southern Oscillation on NSW Coastal Storm Severity, Journal of Coastal Research, vol 24 Sp No.2, pp203-207.

Qi, H., Cai, F., Lei, G., Cao, H., and Shi, F. 2010. The Response of Three Beach Types to Tropical Storms in South China, Marine Geology, accepted for publication. June. 